\title{
Ecological considerations for intervention strategy in the development of eye health promotion policy in South Africa
}

\begin{abstract}
Author:
Hlupheka L. Sithole ${ }^{1}$

Affiliation:

${ }^{1}$ School of Interdisciplinary

Research and Graduate

Studies, University of

South Africa, South Africa

Correspondence to:

Lawrence Sithole

Email:

sithohl@unisa.ac.za

Postal address:

PO Box 392, University of

South Africa 0003, South Africa

\section{Dates:}

Received: 08 June 2015

Accepted: 30 Sept. 2015

Published: 18 Nov. 2015

How to cite this article:

Sithole HL. Ecological

considerations for

intervention strategy in

the development of eye

health promotion policy

in South Africa. Afr Vision

Eye Health. 2015;74(1), Art.

\#314, 6 pages. http://dx.doi/

org/10.4102/aveh.v74i1.314

Note:

This article is partially

based on the thesis of the author in accordance with the requirements for the degree of Doctor of Literature and Philosophy in the subject of Health Studies at the University of South Africa, supervised by Professor O.N. MakhubelaNkondo and co-supervised by Professor O.A. Oduntan, which is available at: http:// uir.unisa.ac.za/bitstream/ handle/10500/11833/thesis sithole_hl.pdf?sequence $=1$
\end{abstract}

\section{Read online:}

Eye health promotion is an important component of public health. To realise the essential aspects of eye health promotion, the formulation and implementation of policy as an intervention strategy is a major contributory factor and can best be described by an ecological framework. Ecological perspectives assert that people's health affairs cannot be neatly grouped into diagnoses, symptoms and risk factors to be targeted and eliminated; this is because the core concept of an ecological model is that behaviour has many levels of influence, often including intrapersonal, interpersonal, organisational, physical environmental, and policy. Therefore, societal and personal issues can be directly linked to an ecological model that points to issues of numerous levels of influence on certain behaviours that affect the manner in which eye care services are utilised. These behaviours are therefore termed salient beliefs. Unfortunately, there is no study in South Africa that has identified the set of beliefs that are salient in any given population that might be responsible for influencing the uptake of eye care services. However, reorienting eye health care services through direct policy reforms and advocacy may change the landscape of eye health care services in South Africa.

\section{Introduction}

The formulation of health policy as an intervention strategy is an important development in health promotion research. It recognises the necessity of incorporating into policy formulation, specific elements that should be considered in the process of formulating an intervention strategy and these may be encapsulated in a conceptual framework. ${ }^{1}$ There are a number of models that can be used as part of a conceptual framework to develop an intervention strategy. However, the researcher wishes to introduce an ecological perspective for the purpose of enlightening optometrists about this model. The term ecology is derived from biological science and refers to the interrelations between organisms and their environments. Ecological models, as they have evolved in behavioural sciences and public health, focus on the nature of people's interactions with their physical and sociocultural surroundings, that is, their environments. ${ }^{1}$

According to Richard, Gauvin and Raine, ${ }^{2}$ ecological models are important for research, programme planning and evaluation, and therefore should be considered when contemplating intervention strategies. In the wake of the absence of an eye health promotion model ${ }^{3}$ in South Africa, it is important for policymakers in government and health researchers, especially optometrists and ophthalmologists in research environments, to be conversant with conceptual frameworks that can be considered in the development of an eye health promotion policy in South Africa.

\section{Ecological framework for health promotion}

Ecological approaches to health issues and ecological models of intervention have become distinctive features of disease prevention and health promotion in public health. ${ }^{2}$ Ecological models have a long history as they emerged from developments in many disciplines and fields (e.g. public health, sociology, biology, education, psychology) which in turn converged to form the ecological and behavioural foundations for health promotion. ${ }^{4}$ Contemporary developments have reinforced their relevance to the field of public health. In particular, the resurgence of interest in social inequalities in health has directed interest into the central role of larger contextual determinants of health, such as socioeconomic factors, gender, and other social and cultural influences. ${ }^{2}$

From an ecological perspective, people's health affairs cannot be neatly grouped into diagnoses, symptoms and risk factors to be targeted and eliminated or altered. ${ }^{5}$ The core concept of an 
ecological model is that behaviour has numerous levels of influence, often including intrapersonal (psychological), interpersonal (social, cultural), organisational, physical environmental, and policy. Ecological models are therefore believed to provide comprehensive frameworks for understanding the many and interacting levels of these behaviours. Most importantly, ecological models can be used to develop comprehensive intervention approaches that systematically target mechanisms of change at each level of influence. $^{6}$

\section{Levels of behavioural influence Intrapersonal (psychological) influence}

According to Ajzen and Fishbein, ${ }^{7}$ the theory of reasoned action and its extension (the theory of planned behaviour ${ }^{8}$ have been found to predict and explain a wide range of behaviours in terms of a limited set of constructs that include attitude towards the behaviour, subjective norm, perceived behavioural control, and behavioural attention. In a study by Ntsoane and Oduntan, ${ }^{9}$ it was reported that some of the factors that influence the use of eye care services in South Africa are societal and personal in nature. Societal and personal issues can therefore be directly linked to an ecological model that points to issues of numerous levels of influence to certain behaviours. These behaviours are therefore termed salient beliefs. ${ }^{10}$ Salient behavioural beliefs are beliefs about the consequences of performing a behaviour whilst salient normative beliefs are held to determine a subjective norm, and salient control beliefs are held to determine perceived behavioural control. In a study by Marmamula et al., ${ }^{11}$ person-related barriers to uptake of eye care services in South India were found to be more common, thus confirming the complexity of ecological association with determinants of using health care services in general.

A study by Fletcher et al. ${ }^{12}$ concluded that a high proportion of people in rural India who could have benefited from eye treatment were not using available services. The study established that fear (principally of eye damage), cost (direct and indirect), family responsibilities, ageism, fatalism, and an attitude of being able to cope (with low or no vision) were the principal barriers to the uptake of eye care services. Marmamula et al. ${ }^{11}$ concluded that intensive awareness campaigns are needed to bring behavioural changes amongst individuals to improve the uptake of services. However, Abdulla, Alsharqi and Abdualla, ${ }^{13}$ acknowledged that barriers to the uptake of services are complex and multidimensional and that interventions must be multifaceted from a theoretical perspective. Therefore, the ecological model theory introduced in the present review should be considered in line with the following salient beliefs for better intervention strategy and policy formulation.

\section{Behavioural beliefs}

Behavioural beliefs are beliefs that determine how strongly individuals consider the consequences of using any available service for their own benefits. ${ }^{14}$ Considerations for seeking eye care services are factors in behavioural beliefs. People with visual impairment or any other eye condition may believe that seeking eye care services in clinics or hospitals may not yield significant results.

\section{Normative beliefs}

These beliefs refer to the views of 'significant others' within a family or community. ${ }^{10}$ If these important people support the notion to seek eye care services, the affected individual will tend to do so, ${ }^{14}$ which thus explains the potential for significant people in families to play a major role in influencing decisions. Conversely, if they believe that seeking eye care services at established institutions is not important, the sufferers may opt not to take up the available services as they may not wish to disappoint the significant people.

\section{Control beliefs}

This concept refers to beliefs about factors that may facilitate or impede performance of a behaviour. ${ }^{10}$ Certain parents may not independently take their children for an eye checkup without the influence of others. They may also not allow their children to undergo vision screenings at school without permission from significant others.

Unfortunately, there is no study in South Africa that has identified the set of beliefs that are salient in any given population and that might be responsible for influencing the uptake of eye care services. Sutton et al. ${ }^{10}$ recommend that an elicitation study in a representative population sample should be conducted so that salient beliefs and their ecological associations may be determined. These could then be used in the formulation of intervention strategies at a policy level.

\section{Interpersonal (social and cultural beliefs)}

The age and gender of members of a given community need to be factored into any intervention strategy. Children and adult women have their own specific needs, as opposed to the needs of the elderly. In a South African study conducted by Nojilana et al., ${ }^{15}$ it was reported that vitamin A deficiency was found to be a problem in one-third of children aged between $0-4$ years and $1 \%-6 \%$ of pregnant women. Vitamin A deficiency can cause xerophthalmia and even lead to blindness. ${ }^{16}$ Therefore, intervention strategies should include vitamin A supplementation amongst this population group.

Furthermore, the Health System Trust has estimated that $10 \%$ of children and $80 \%$ of adults over the age of 40 years in South Africa need refractive services and correction. ${ }^{17}$ Unfortunately, visual problems are a leading cause of disability in South Africa, and are one of the key barriers to people accessing schooling and the labour market. ${ }^{18}$ This issue should be prominently considered, therefore, in the ecological intervention for eye health promotion and policy development in South Africa.

A cultural practice that may also be a risk factor for poor eye health is the use of traditional eye medicine (TEM). 
According to Courtright, ${ }^{19}$ TEM instilled directly into the eye is usually responsible for poor visual outcomes. It damages the eye owing to the cornea being exposed to micro-organisms that lead to infection. With a reported $70 \%$ $-80 \%{ }^{20}$ of people in South Africa using TEMs, it is possible that they are causing serious eye health problems. Therefore, the use of TEM may need to be considered in the eye care model formulation.

\section{Physical environment}

The major structural barriers to health in Africa are regulative measures that hinder the practice of good health. ${ }^{21}$ Poor practitioner-to-patient ratios, poor state funding and lack of educational programmes are characteristic of health care in Africa. ${ }^{22}$ These barriers may also be physical owing to lack of water and adequate sanitation, contamination of water, poorly ventilated housing, overcrowding and improper waste disposal, which become breeding grounds for infectious and parasitic diseases. ${ }^{23}$ The unhygienic conditions in rural and urban areas are enabling environments for infectious diseases that may prove difficult to control. These challenges need to be addressed as part of an ecological intervention strategy.

According to Ntsoane and Oduntan, ${ }^{9}$ access to eye care services can also be measured by travel time to the nearest eye care facility. Therefore, poor accessibility owing to distance and a lack of eye care facilities in the immediate vicinity can be a major determinant for eye care seeking behaviour in South Africa. Consequently, when issues of eye health promotion are considered, it may be important to also look at physical infrastructure such as roads and transport systems for better accessibility to eye care services, especially in rural areas.

\section{Organisational influences}

According to the World Health Organization, ${ }^{24}$ there are a number of factors influencing the success and failure of public health programmes that include, among others, the following factors.

\section{National planning}

Public health interventions need to address all the direct and indirect influences of the population's health and take action on many fronts to achieve success. Unfortunately, as indicated earlier, there is no directorate or policy for eye health care in South Africa. This hiatus will continue to be a major problem for eye health care services if significant decisions are not made soon.

\section{Approaches to health promotion and disease prevention}

According to Truett, Cornfield and Kannel (1967), ${ }^{25}$ there are various approaches to health promotion and disease prevention. Two basic approaches are:

- to look at the underpinning influences of health, such as poverty, education, socio-economic standing, etc.
- to look at specific risk factors for a specific health outcome, for example, obesity, hypertension and lack of exercise, which may be predisposing factors for retinal diseases.

\section{Immunisation programmes}

Immunisation of children at an early age plays a major role in eliminating potentially blinding diseases such as measles which is an important cause of serious eye complications. ${ }^{26}$ For example, conjunctivitis and keratitis are common complications of measles. Viral (adenovirus) and bacterial infections (Pseudomonas or Staphylococcus) can lead to permanent scarring of the cornea and consequent blindness. ${ }^{27}$ Furthermore, measles associated with Vitamin A deficiency is a predisposing factor for more severe keratitis, corneal scarring and blindness in developing countries. ${ }^{28}$ Therefore, immunisation against measles should be an important part of eye health promotion in the proposed policy development for South Africa.

\section{Availability of relevant and reliable data on target population}

According to Rigby and Kohler:

Reliable, relevant data are needed to judge the success of any programme. Data collection is the starting-point to knowing whether, at population level, a health promotion intervention should be instituted and whether it is effective. Such data collection needs to be at the national, provincial and local level to assess epidemiological prevalence, political willingness, health system capacity and community preferences. ${ }^{29}$

\section{Socio-economic factors}

Socio-economic factors are major determinants of health in children, young people and adults. ${ }^{29}$ If the population is of a high economic level, the prevalence of a given health problem may be already low and, as such, the intervention may not reach a significant level. However, if the population is of a low economic level, the intervention may have a more significant effect. ${ }^{29}$

There is also increasing recognition of the need to highlight the link between poverty, development and health care. ${ }^{30}$ Poverty can exert a negative influence on the development and intellectual aspects of children's health independently of the educational levels of their parents. ${ }^{31}$

\section{Mass media programmes}

Media campaigns are used in an attempt to influence various health behaviours in mass populations. ${ }^{32}$ There is some evidence that mass media campaigns are effective to that effect. ${ }^{33}$ Typical campaigns have placed messages in media that reach large audiences such as TV and radio, but also outdoor media such as billboards and posters, and print media such as magazines and newspapers. New technologies such as mobile phones and other personal digital assistants are also being used to influence change in behavioural patterns. ${ }^{32}$ These campaigns have the ability to disseminate well-defined, behaviourally focused messages 
to large audiences repeatedly, over time, in an incidental manner, and at low cost per person.

According to Guldan, ${ }^{34}$ it is generally accepted that mass media are particularly appropriate when the behaviour changes to be promoted are simple and there are no significant barriers to the community taking action. With more difficult behaviours, especially those that are underpinned by strong cultural beliefs, mass media need to be supplemented by more sensitive community-based approaches. Although face-to-face discussions might be slower and more labourintensive, they provide opportunities for direct engagement and participation of individual communities ${ }^{35}$ and should therefore be encouraged.

\section{School health programmes}

In a study by Sithole, ${ }^{36}$ school health programmes were reported to be the most prominent health promotion activities in South Africa and have also been proven to achieve some goals in health promotion by various researchers. ${ }^{37}$ The aim of school health programmes is to achieve healthy lifestyles for the total school population by developing supportive environments conducive to health promotion. These programmes offer opportunities for, and require commitments to, the provision of a safe and healthenhancing social and physical environment. ${ }^{37}$

According to Booth and Samdal, ${ }^{38}$ the literature generally sets out three components or domains of activity that characterise the school health programmes approach:

- the formal health curriculum that gives school-aged children the essential knowledge and social skills that will allow them to make enlightened choices affecting their physical and psychosocial health

- the school environment and the school climate, the health services and policies of the school

- the school/community interaction.

The school health programmes approach requires a substantial change in the way that schools and their staff practise school health. This change involves moving from practices that rely mainly on classroom-based health education models to a more comprehensive, integrated construct of health promotion that focuses both on children's attitudes and behaviours, and their environment ${ }^{39}$ which is an ecological perspective of addressing eye health promotion.

\section{Policy}

The recognition of legislation and health policy to guide eye health processes in South Africa could be regarded as a failure. Although apartheid played a major role in pooling eye care resources in certain areas only, such as Elim Hospital in Limpopo Province, such an unfortunate era should not be playing a role in the democratic South Africa of today. Historical imbalances, in terms of urban and rural curative focus, still persist in the current delivery of eye health care services. Primary eye health care has not improved since 1994 as there continues to be no knowledge of statistical records on eye care across South Africa. Some provinces (e.g. Western Cape) even contract private eye care practitioners to service citizens in their region. ${ }^{36}$ Although such an initiative may be working, it further reveals the degree to which South Africa has diversified eye care services across all provinces, to the extent that eye health promotion is non-existent. Consequently, the private sector is the provider of most basic eye care services including eye health promotion in South Africa.

The current private-public split is therefore an important factor to consider in eye health-related policy development and planning. Also, the current biomedical influences on undergraduate training means that more eye care professionals, especially optometrists, will choose to work in the lucrative private market that is dominated by competitive monopoly ${ }^{40}$ rather than join the public health care system. This state is also reflected in the attrition of the public health sector workforce in favour of the private sector or for overseas work contracts. However, the bureaucracy in the public health sector could also act as a hindrance to improving the public health sector eye health workforce through barriers in employment opportunities and affirmative action policies. Furthermore, it would only benefit the public health sector if undergraduate optometry students were allowed to serve one year of internship before being allowed to leave for private sector contracts. This policy would in turn give more impetus to any eye health promotion strategies as there would be more human resources for such initiatives.

\section{Reorientation of health services (service delivery)}

In view of the current situation in eye health promotion in the South African primary health care system, it is therefore important to consider restructuring eye health services delivery as a matter of urgency. Although the proposed national health insurance plan may provide some positive results in this regard, changes in eye care and particularly in eye health promotion may take too long to be effected. This may largely be because of the lack of political will to formulate structures and systems that will pave the way for establishing a directorate for eye health care and the development of an eye health care policy. In consideration of the interaction between the environment and individuals from an ecological perspective, it is therefore important that health promotion takes place alongside improvement in services as adopted in the Ottawa Charter, ${ }^{41}$ as shown in Table 1. In addition, improvement should also address locally identified barriers, which might include quality of clinical care as well as the other non-clinical aspects of care; for example, timing of clinics and operating sessions; ensuring men and women have separate waiting areas; and ensuring a clean environment. ${ }^{34}$ There is also a need to improve the quality of information provided to patients to promote adherence to treatment regimens and follow-up, to increase awareness of possible side-effects, and action needed to prevent recurrence. Implementing patient education in resource-poor settings with crowded clinics 
TABLE 1: The different areas of activity for eye health promotion as adopted in the Ottawa Charter in 1986.

\begin{tabular}{lll}
\hline $\begin{array}{l}\text { Health education: directed } \\
\text { at individuals, families and } \\
\text { communities to promote }\end{array}$ & $\begin{array}{l}\text { Service improvement: } \\
\text { improvement in the quantity } \\
\text { and quality of services }\end{array}$ & $\begin{array}{l}\text { Advocacy: for policies } \\
\text { that promote eye health }\end{array}$ \\
\hline $\begin{array}{l}\text { Eye health-promoting } \\
\text { behaviours, e.g. face } \\
\text { washing }\end{array}$ & Eye care & $\begin{array}{l}\text { Support for expansion of } \\
\text { eye health services and } \\
\text { disease prevention }\end{array}$ \\
$\begin{array}{l}\text { Uptake of services } \\
\text { Patient education }\end{array}$ & $\begin{array}{l}\text { Economic support to } \\
\text { increase affordability of } \\
\text { preventive actions }\end{array}$ \\
$\begin{array}{l}\text { Support for mass } \\
\text { treatment }\end{array}$ & Community outreach & $\begin{array}{l}\text { Provision of water, } \\
\text { housing and land }\end{array}$ \\
$\begin{array}{l}\text { Promotion of awareness, } \\
\text { knowledge, decision } \\
\text { making, beliefs, attitudes, } \\
\text { empowerment }\end{array}$ & $\begin{array}{l}\text { Supplies of drugs } \\
\text { Vector control }\end{array}$ & $\begin{array}{l}\text { Safety legislation } \\
\text { Food policy/fortification }\end{array}$ \\
& $\begin{array}{l}\text { spectacles } \\
\text { School health }\end{array}$ & \\
\hline
\end{tabular}

Source: Adapted from Hubley J, Gilbert C. Eye health promotion and prevention of blindness in developing countries: Critical issues. Br J Ophthalmol. 2006;90:279-284. PMID: 16488944, http://dx.doi.org/10.1136/bjo.2005.078451

and shortages of health workers is challenging ${ }^{34}$ and may not be possible if there are no guidelines to provide clear directives - as is unfortunately the case now in South Africa.

\section{Conclusion}

In the context of an ecological perspective, it is important to realise that people's interactions with their environment is, to a certain extent, influenced by public policy. Public policy determines actions to be adopted by public and private entities and eventually contributes immensely to measures that are employed to nurture health. However, a political will is required to engage researchers, academics and private practitioners to overhaul the current eye care model in South Africa. Proposals for the establishment of a new directorate for eye health care have been made but there seems to have been not much progress to date, thus further showing that there is no adequate political influence that can see some of the ecological perspectives, as described in the present review, being incorporated into a dream of eye health promotion intervention strategy in South Africa.

\section{Acknowledgements Competing interests}

The author declares that there are no financial or personal relationships which may have inappropriately influenced the writing of this article.

\section{References}

1. Sallis F, Cervero RB, Ascher W, Henderson KA, Kraft MK, Kerr J. An ecological approach to creating active living communities. Annu Rev Public Health 2006;27:297-322. PMID: 16533119, http://dx.doi.org/10.1146/annurev. publhealth.27.021405.102100

2. Richard L, Gauvin L, Raine K. Ecological models revisited: Their uses and evolution in health promotion over two decades. Annu Rev Public Health. 2011;32:307-326. PMID: 21219155, http://dx.doi.org/10.1146/annurev-publhealth-031210-101141

3. Sithole HL, Oduntan OA. Eye health promotion in the South African primary health care system. S Afr Optom. 2010;69:200-206.

4. Green LW, Richard L, Potvin L. Ecological foundations of health promotion. Am J health Promot. 1996;10:270-281. PMID: 10159708, http://dx.doi.org/10.4278/ 0890-1171-10.4.270

5. Milio, N. Making healthy public policy: Developing the science by learning the art: An ecological framework for policy studies. Health Promot. 1987;2:263-274. PMID: 10303001, http://dx.doi.org/10.1093/heapro/2.3.263
6. Newes-Adeyi G, Helitzer DL, Caulfied LE, Bronner Y. Theory and practice: Applying the ecological model to formative research for a WIC training program in New York State. Health Educ Res. 2000;15:283-291. PMID: 10977376, http://dx.doi. York State. Health Educ Res.
org/10.1093/her/15.3.283

7. Ajzen I, Fishbein M. Understanding attitudes and predicting social behaviour. Englewood Cliffs: Prentice-Hall; 1980.

8. Ajzen I. The theory of planned behaviour. Organ Behav Hum Decis Process. 1991;50:179-211. http://dx.doi.org/10.1016/0749-5978(91)90020-T

9. Ntsoane MD, Oduntan $\mathrm{OA}$. A review of factors influencing the utilization of eye care services. S Afr Optom. 2010;69:182-192.

10. Sutton S, French DP, Hennings SJ, et al. Eliciting salient beliefs in research on the theory of planned behaviour: The effect of question wording. Curr Psychol. 2003;22:234-251. http://dx.doi.org/10.1007/s12144-003-1019-1

11. Marmamula S, Khanna RC, Shekhar K, Rao GN. A population-based crosssectional study of barriers to uptake of eye care services in South India: The Rapid Assessment of Visual Impairment (RAVI) project. BMJ Open. $2014 ; 4$
PMID: 24928590, http://dx.doi.org/10.1136/bmjopen-2014-005125

12. Fletcher $A E$, Donoghue $M$, Devaram J, et al. Low uptake of eye services in rural India: A challenge for programs of blindness prevention. Arch Ophthalmol. $1999 ; 117: 13$
10.1393

13. Abdulla KN, Al-Sharqi OZ, Abdulla MT. Barriers to the uptake of eye care services in the developing countries: A systematic review of interventions. J Health Educ. 2013;72:742-754. http://dx.doi.org/10.1177/0017896912461193

14. Bamberg S. How does environmental concern influence specific environmentally related behaviours? A new answer to an old question. J Environ Psychol. 2003;23:21-32. http://dx.doi.org/10.1016/S0272-4944(02)00078-6

15. Nojilana B, Norman R, Bradshaw D, et al. Estimating the burden of disease attributable to vitamin A deficiency in South Africa in 2000. S Afr Med J. 2007;97:748-753. PMID: 17952233.

16. Christian $\mathrm{P}$, West KP, Jr, Khatry SK, et al. Night blindness during pregnancy and subsequent mortality among women in Nepal: Effects of vitamin A and $\beta$-carotene supplementation. Am J Epidemiol. 2000;152:542-547. PMID: 10997544, http:// dx.doi.org/10.1093/aje/152.6.542

17. Lewis K, Patel D, Yorston D, Charteris D. A qualitative study in the United Kingdom of factors influencing attendance by patients with diabetes at ophthalmic outpatient clinics. Ophthalmic Epidemiol. 2007;14:375-380. PMID: 18161611, http://dx.doi.org/10.1080/09286580701375195

18. Palagyi A, Ramke J, du Toit R, Brian G. Eye care in Timor-Leste: A population-based study of utilization and barriers. Clin Experiment Ophthalmol. 2008;36:47-53. PMID: 18190597, http://dx.doi.org/10.1111/j.1442-9071.2007.01645.x

19. Courtright P. Eye care knowledge and practices among Malawian traditional healers and the development of collaborative blindness prevention programmes. Soc Sci Med. 1995;41:1569-1575. PMID: 8607046, http://dx.doi.org/10.1016/02779536(95)00028-6

20. Kasilo O. Traditional African medicine. Paper presented at: Better science, policy and services for health development. Proceedings of a WHO international symposium; 2000 Sep 11-13; Awaji Island, Japan.

21. Naidoo K. Poverty and blindness in Africa. Clin Exp Optom. 2007;90:415-421. PMID: 17958563, http://dx.doi.org/10.1111/j.1444-0938.2007.00197.x

22. Thylefors $B$, Negrel AD, Pararajesegaram R, Dadzie KY. Global data on blindness. Bull World Health Organ. 1995;73:115-121. PMID: 7704921.

23. Govender RD. The barriers and challenges to health promotion in Africa. S Afr Fam Pract. 2005;47;39-42. http://dx.doi.org/10.1080/20786204.2005.10873303

24. Word Health Organization. What are the main factors that influence the implementation of disease prevention and health promotion programmes in children and adolescents? Copenhagen: World Health Organization; 2005.

25. Truett J, Cornfield J, Kannel W. A multivariate analysis of risk of coronary heart disease in Framingham. J Chronic Diseases. 1967;20:511-524.

26. Perry RT, Hasley NA. The clinical significance of measles: A review. J Infect Dis. 2004;189:S4-S16. PMID: 15106083, http://dx.doi.org/ 10.1086/377712

27. Foster A, Sommer A. Childhood blindness from corneal ulceration in Africa: Causes, prevention, and treatment. Bull World Health Organ. 1986;64:619-623. PMID: 3492298.

28. Wairagkar NS, Gandhi BV, Katrak SM, et al. Acute renal failure with neurological involvement in adults associated with measles virus isolation. Lancet. 1999;354:992-995. PMID: 10501362, http://dx.doi.org/10.1016/S0140-6736(98) 10101-0

29. Rigby M, Kohler L, editors. Child health indicators of life and development: Report to the European Commission. Luxembourg: European Union Country Health Monitoring Programme; 2002.

30. Spencer N. Poverty and child health. 2nd ed. London: Radcliffe Medical Press; 2000.

31. Bradley RH, Corwyn RF. Socioeconomic status and child development. Annu Rev Psychol. 2002;53:371-399. PMID: 11752490, http://dx.doi.org/10.1146/annurev. psych.53.100901.135233

32. Wakefield MA, Loken BL, Hornik RC. Use of mass media campaigns to change health behaviour. Lancet. 2010;376:1261-1271. PMID: 20933263, http://dx.doi. org/10.1016/S0140-6736(10)60809-4

33. Boles M, Adams A, Gredler A, Manhas S. Ability of a mass media campaign to influence knowledge, attitudes, and behaviours about sugary drinks and obesity. Prev Med. 2014;67:S40-S45. PMID: 25066020, http://dx.doi.org/10.1016/j. ypmed.2014.07.023 
34. Guldan GS. Obstacles to community health promotion. Soc Sci Med. 1996;43:689695. PMID: 8870133, http://dx.doi.org/10.1016/0277-9536(96)00114-1

35. Hubley J, Gilbert C. Eye health promotion and prevention of blindness in developing countries: Critical issues. Br J Ophthalmol. 2006;90:279-284. PMID: 16488944, http://dx.doi.org/10.1136/bjo.2005.078451

36. Sithole HL. Critical analysis of the South African health care policies and programmes with regards to eye health promotion [DLitt et Phil Thesis]. Pretoria: UNISA; 2013.

37. Moon AM, Mullee MA, Rogers L, Thompson RL, Speller V, Roderick P. Helping schools to become health-promoting environments - An evaluation of the Wessex healthy schools award. Health Promot Int. 1999;14:111-122. http://dx.doi. org/10.1093/heapro/14.2.111
38. Booth ML, Samdal O. Health-promoting schools in Australia: Models and measurements. Aust N Z J Public Health. 2008:21:365-370. PMID: 9308200 http://dx.doi.org/10.1111/j.1467-842X.1997.tb01716.x

39. Deschesnes M, Martin C, Hill AJ. Comprehensive approaches to school health promotion: How to achieve broader implementation? Health Promot Int. 2003;18:387-396. PMID: 14695370, http://dx.doi.org/10.1093/heapro/ dag 410

40. Singh S, Myburgh NG. A critical analysis of the provision for oral health promotion in South African health policy analysis. Final report. Durban: Health Systems Trust; 2005.

41. Word Health Organization. Ottawa charter for health promotion. Ottawa: Canadian Public Health Association; 1986. 